\title{
Selected non-communicable diseases and risk conditions among fishermen in Divisional Secretariat Division of Kalpitiya
}

\author{
S.R.A.P. Harshani ${ }^{1}$, H.T.C.S. Abeysena ${ }^{2 *}$
}

\begin{abstract}
Background

Fishermen are special group of people who are more vulnerable to non-communicable diseases due to occupation specific conditions.
\end{abstract}

\section{Objective}

To determine the prevalence of accidental injuries, hypertension, malnutrition, smoking and alcohol consumption among fishermen in Divisional Secretariat Division of Kalpitiya.

\section{Methods}

This was a descriptive cross-sectional study, conducted during the period of August to October 2011. The sample consisted of 465 fishermen with $\geq 6$ months experience in fishing and selected by applying the cluster sampling technique. The study instruments were the interviewer-administered questionnaire and the record sheet. Prevalence of the above conditions and diseases with $95 \%$ confidence intervals $(\mathrm{CI})$ were calculated.

\section{Results}

The prevalence of accidental injuries was 19.6\%(95\%CI:16\%-23.2\%). The prevalence of hypertension was $24.3 \%(95 \% \mathrm{CI}: 20.4 \%-28.2 \%)$ and it was significantly higher among those who have $>10$ years of service experience in the fishing sector $(\mathrm{p}<0.01)$ and history of smoking $>10$ years duration $(\mathrm{p}<0.001)$. The prevalence of underweight, overweight and obesity were $6.2 \%(95 \% \mathrm{CI}: 4 \%$ $8.4 \%$ ), 20.6\%(95\%CI:16.9\%-24.3\%) and 2.6\%(95\%CI:1.2\%-4\%) respectively. The prevalence of current smokers and current alcohol consumers were 54.6\%(95\% CI: $50.2 \%-59 \%)$ and $60.2 \%(95 \%$ CI: 55.8\%-64.6\%) respectively.

\section{Conclusion}

The prevalence of hypertension, smoking and alcohol consumption were higher and obesity was lower among fishermen than general population. Improve the knowledge on prevention and screening are recommended.

Key words: alcohol, fishermen, hypertension, obesity, overweight, smoking

\section{Introduction}

Non communicable diseases (NCD) are rising with increasing threat to health sector. Fishermen are more vulnerable to NCD as majority of them have lifestyle risk factors (1).
Risks of health problems vary with the type of fishing operation, area of operation, vessel size, equipment carried and the job of each fisherman. When compared to small vessels, fishermen in larger vessels have higher risk of injury or death through crushing by heavy equipment. Bad weather, loss of power and unsuitable vessels are

1. Medical Officer, Ministry of Health, Nutrition and Indigenous Medicine, Sri Lanka 2. Professor in Public Health, Faculty of Medicine, University of Kelaniya, Sri Lanka *Correspondence: chrishantha-abeysena@kln.ac.lk DOI: $10.4038 /$ jccpsl.v22i1.8083 
additional risks, which may be greater for small vessels than larger ones. Smaller vessels may be damaged or lost more easily by powerful storms or run down by merchant ships (2).

The International Labour Organization's (ILO) Occupational Safety and Health Branch estimates that fishing has a worldwide fatality rate of 80 per 100,000 workers or approximately 24,000 deaths per year, and estimates that there are 24 million non-fatal accidents in the sector annually (2). There is a great variety in fishing operations and also a great variety in the way health problems of fishermen are classified.

Kaerlev, L et al reported fishermen have high standardised incidence ratio for injuries compared to general population (3). Similarly Roberts SE reported the fatal accident rate among fishermen was 115 times greater than in the general British workforce (4). This study showed that commercial fishing is by far the most hazardous occupation in Britain (4). Another study had reported there were 60 workplace deaths and 574 hospitalized injuries among the fishermen during the period 19911998 (4). Casson et al reported fishermen had a higher prevalence of work injuries compared to a reference working group (6). The prevalence of the work related injuries among the fishermen was $38.6 \%$ in North Carolina (7). In many cases, the consequence of an accident is more severe when it happens in the sea than if it happened on land (8).

Kirkutis et al reported that the prevalence of hypertension among the Lithuanian seamen was $44.9 \%$ (9). Roberts SE reported that most of the deaths of fishermen were caused by cardio vascular diseases, and probably due to lifestyle risk factors as well as extremely hazardous and stressful working and sleeping conditions (1).

Fishermen have other risk conditions of NCDs like obesity due to high amount of fish intake with low priority to other nutrients especially in long voyages. The prevalence of the overweight among fishermen was reported as $73.3 \%$ high in Denmark (10). Heavy smoking due to work at night and alcohol intake may be related to overwork and tiredness. The prevalence of the current smoking, reported by the Lawrie et al was $38.4 \%$ and the prevalence of the alcohol consumption was $80.6 \%$ among the fishermen in Scotland (11). Casson et al reported significantly increase risk of ill health in the fishermen was associated with higher levels of smoking and longer hours of working (6).

In Sri Lanka fishing fleets has increased significantly over the last ten years. Multi day boats have increased almost two folds. Nonmotorized traditional boats comprise of a $38 \%$ of the fishing fleet, which shows the under developed nature of the fishing industry in Sri Lanka (12).

Accidents and illnesses in the fishing industry are costly as in any other occupation. The fishermen have to bear pain and loss of income without any compensation and sometimes even lose their lives. The family has to share the suffering, as well as the stress that comes from knowing fishing is a dangerous profession. As fishing community is a special type of group, one cannot generalize the national mortality and morbidity rates to them. The objective of the study was to determine the prevalence of accidental injuries, hypertension, malnutrition, smoking and alcohol consumption among fishermen in Divisional Secretariat Division of Kalpitiya.

\section{Methods}

This was a descriptive cross sectional study, conducted among fishermen in Divisional Secretariat Division of Kalpitiya during the period of August to October 2011. The study population consisted of fishermen with more than 6 months experience in fishing. Details of this study have been published elsewhere (13). 
The sample was chosen by applying cluster sampling method. The cluster was a fishing village, which has more than 100 fishing households. There are 10 such clusters in 28 fishing villages in the area. Of them five clusters were selected randomly and 93 eligible fishermen recruited from each cluster to fulfill the calculated sample size of 465 . In each selected cluster, the index house was randomly selected from the main road. Then the houses of left side of the index house were visited till the required numbers of fishermen were recruited. If there were more than one eligible fisherman living in any household, those who had more service duration in fishing, was selected.

The study instruments were the pre-tested interviewer administered questionnaire and the record sheet for recording the measurement of weight, height and blood pressure. The calibrated beam balance was used to measure weight by the standard method. The height was measured by using height measuring tape using the standard method. Blood pressure was measured using standard technique by calibrated manual sphygmomanometer. All the participants were asked to rest for five minutes before each blood pressure measurement made. The reading was tabulated to nearest $2 \mathrm{mmHg}$. Two recordings were taken 5 minutes apart and average blood pressure was taken.

Accidental injuries were defined as an injury that takes place accidentally in relation to fishing during the past six months. Hypertension is defined as when systolic blood pressure is $\geq 140 \mathrm{mmHg}$ and/or diastolic blood pressure $\geq 90 \mathrm{mmHg}$ in more than 2 occasions. Hypertension was classified into three stages; Stage I: 140-159/ 90-99 mmHg, stage II: $160-$ 179/ 100-109 mmHg and stage III: $\geq 180 / 110$ mmHg.

Ever smoker was defined as a person who has smoked any kind of tobacco product during his life time and current smoker was those who have smoked during last one year. Current alcohol drinker was defined as a person who drinks any kind of alcohol during last one year. Ever drinker was defined as a person who has drunken any kind of alcohol product during his life time. Underweight, overweight and obesity were defined based on body mass index (BMI) as $<18.5 \mathrm{~kg} / \mathrm{m}^{2}, 25 \mathrm{~kg} / \mathrm{m}^{2}$ to $29.9 \mathrm{~kg} / \mathrm{m}^{2}$ and $>30$ $\mathrm{kg} / \mathrm{m}^{2}$ respectively.

Data analysis was done using Statistical Package for Social Sciences (SPSS) 16th version. The prevalence of health problems were expressed with $95 \%$ confidence intervals. Chi square test was performed to assess the difference of prevalence between the categories of selected independent variables. Multiple logistic regression was performed where eligible for controlling confounding effects and results were expressed as odds ratio (OR) and the $95 \%$ confidence interval.

Informed written consent was obtained from the participants. Those who need treatment were referred to the relevant clinics. Ethical clearance was granted from the Ethical Review Committee of the Faculty of Medicine, University of Colombo.

\section{Results}

A total of 465 fishermen participated and the response rate was $100 \%$. The mean age of the study participants was $38.2 \pm 19.3$ years and majority of them were in the age group of 25-35 years $(30 \%)$, Sinhalese $(61.5 \%)$, Catholics $(80$ $\%)$ and married ( $85.4 \%)$ and $58 \%$ educated grade 6 and above. A majority of fishermen (52.7\%) worked in single day motor boats and spent less than one day in the boat for a trip $(94.2 \%)$. The monthly income of a majority (47.5\%) was less than Rs. 10000.

\section{Prevalence of accidental injuries}

Accidental injuries were reported in 91 of fishermen during last 6 months. Therefore the 
prevalence of accidental injuries was $19.6 \%$ (95\% CI: 16\%-23.2\%). Most of the injuries were lacerations $(\mathrm{n}=53,11.4 \%)$ followed by crush injuries $(\mathrm{n}=28,6 \%)$, abrasions $(\mathrm{n}=9,1.9 \%)$ and one $(0.2 \%)$ amputation. Most of the injuries were reported from arms $(\mathrm{n}=53,11.4 \%)$, followed by legs $(n=21,4.5 \%)$, fingers $(n=12,2.6 \%)$ and foot $(n=5,1.1 \%)$. The prevalence of accidental injuries was significantly higher among the fishermen who had educational level of grade 6 and above ( $\mathrm{p}$ value $<.01$ ) and fishermen who work in single day motor boats compared to other boats $(\mathrm{p}<0.02)$ [Table 1].

Table 1 Prevalence of accidental injuries by selected variables

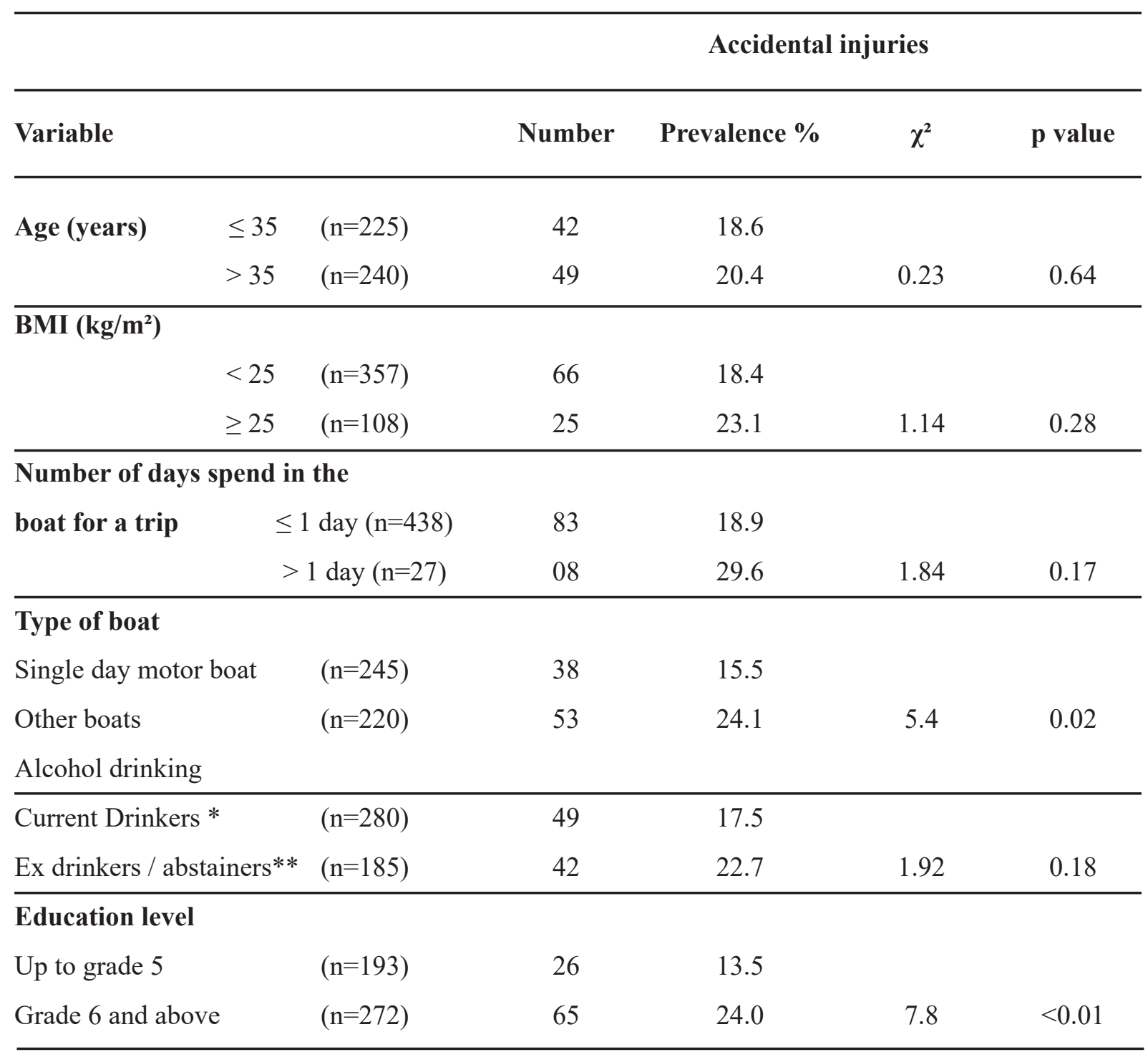

* Those who have no change, has increased or decreased in drinking pattern during last year.

** Those who have never drunken alcohol or not drinking during last year. 


\section{Prevalence of hypertension}

Of 465 fishermen 113 had hypertension, therefore the prevalence of hypertension was $24.3 \%$ (95\% CI:20.4\%-28.2\%). Of them majority 112 (24\%) had stage I hypertension and only one $(0.2 \%)$ suffered from stage II hypertension. The prevalence of hypertension was significantly higher among those who had $>10$ years' service duration in fisheries sector $(\mathrm{p}<0.01)$ and who smoke cigarettes $>10$ years $(\mathrm{p}<0.001)$ (Table 2 ). According to multiple logistic analysis, the duration of the service $>10$ years $(\mathrm{OR}=2.4$, 95\%CI; 1.6-3.9) and the duration of the smoking $>10$ years $(\mathrm{OR}=2.0,95 \% \mathrm{CI} ; 1.1-3.8)$ were still remain significantly associated with presence of hypertension (Table 2).

Table 2 Prevalence of hypertension by selected variables

\section{Hypertension}

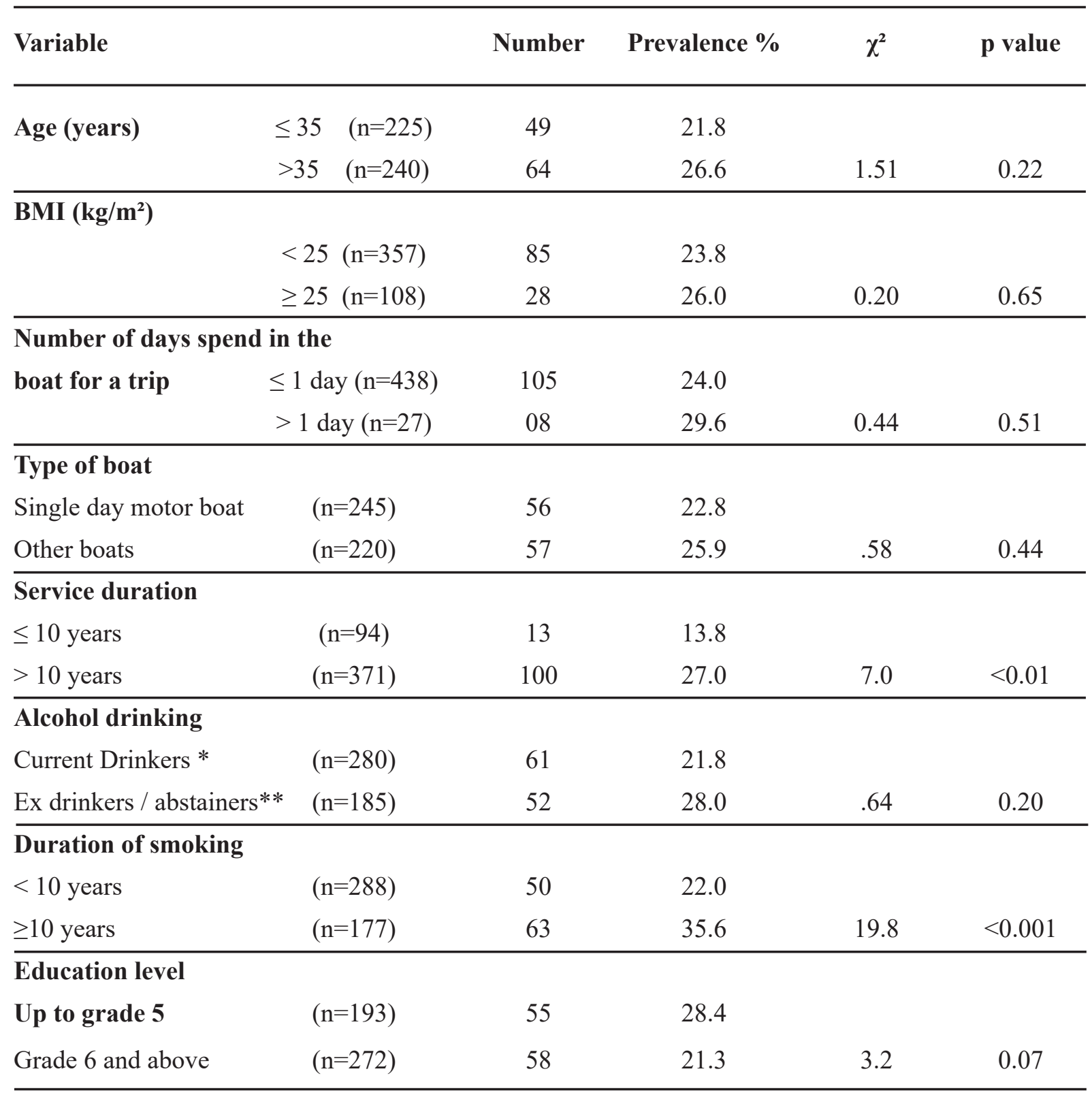

* Those who have no change, has increased or decreased in drinking pattern during last year.

** Those who have never drunken alcohol or not drinking during last year. 


\section{Prevalence of overweight and obesity}

Of 465 fishermen 12 were obese 96 overweight, and 29 underweight. Therefore the prevalence of obesity, overweight and underweight were $2.6 \%$ (95\% CI: $1.2 \%-4 \%), 20.6 \%$ (95\% CI: $16.9 \%-24.3 \%)$ and $6.2 \%$ (95\% CI: $4 \%-8.4 \%)$ respectively.

\section{Prevalence of smoking}

Of 465 fishermen 264 were ever smokers and 254 current smokers. Therefore the prevalence of ever smokers and current smokers were $56.8 \%$
(95\% CI: $52.3 \%-61 \%)$ and $54.6 \%(95 \% \mathrm{CI}$ : $50.2 \%-59 \%$ ) respectively. The prevalence of current smoking was lower among Catholics compared to non-Catholics $(\mathrm{p}<0.01)$ [Table 3].

\section{Prevalence of alcohol consumption}

Of 465 fishermen 284 ever and 280 current alcohol drinkers which gave the prevalence of ever and current alcohol drinkers as 61\% (95\% CI: $56.5 \%-65.3 \%$ ) and $60.2 \%$ (95\% CI: $55.8 \%$ $64.6 \%)$ respectively. The prevalence of current alcohol drinking was higher among Catholics compared to non-Catholics ( $\mathrm{p}<0.001)$ [Table 4].

Table 3 Prevalence of current smoking by selected variables

\section{Current smoking}

\begin{tabular}{|c|c|c|c|c|c|}
\hline Variable & & Number & Prevalence \% & $\chi^{2}$ & p value \\
\hline \multirow[t]{2}{*}{ Age (years) } & $(n=225)$ & 124 & 55.1 & & \\
\hline & $(n=240)$ & 130 & 54.1 & 0.04 & 0.83 \\
\hline \multicolumn{6}{|c|}{ Number of days spend in the boat for a trip } \\
\hline$\leq 1$ day & $(n=438)$ & 236 & 53.8 & & \\
\hline$>1$ day & $(\mathrm{n}=27)$ & 18 & 66.6 & 1.67 & 0.19 \\
\hline \multicolumn{6}{|l|}{ Type of boat } \\
\hline Single day motor boat & $(n=245)$ & 130 & 53.0 & & \\
\hline Other boats & $(\mathrm{n}=220)$ & 124 & 56.4 & 0.51 & 0.48 \\
\hline \multicolumn{6}{|l|}{ Service duration } \\
\hline$\leq 10$ years & $(\mathrm{n}=94)$ & 52 & 55.3 & & \\
\hline$>10$ years & $(n=371)$ & 202 & 54.4 & 0.02 & 0.88 \\
\hline \multicolumn{6}{|l|}{ Ethnicity } \\
\hline Sinhalese & $(\mathrm{n}=286)$ & 146 & 51.0 & & \\
\hline Non-Sinhalese & $(n=179)$ & 108 & 60.3 & 1.64 & 0.20 \\
\hline \multicolumn{6}{|l|}{ Religion } \\
\hline Catholics & $(n=372)$ & 191 & 22.0 & & \\
\hline Non-Catholics* & $(\mathrm{n}=93)$ & 63 & 35.6 & 8.0 & $<0.01$ \\
\hline \multicolumn{6}{|l|}{ Education level } \\
\hline Up to grade 5 & $(n=193)$ & 104 & 53.8 & & \\
\hline Grade 6 and above & $(n=272)$ & 150 & 55.1 & 0.07 & 0.78 \\
\hline
\end{tabular}

* Buddhist, Islam and Hindu 
Table 4 Prevalence of current alcoholics by selected variables

\section{Current Alcoholics}

\begin{tabular}{|c|c|c|c|c|c|}
\hline Variable & & Number & Prevalence \% & $\chi^{2}$ & p value \\
\hline \multirow[t]{2}{*}{ Age (years) } & $(n=225)$ & 131 & 58.2 & & \\
\hline & $(n=240)$ & 149 & 62.0 & 0.72 & 0.39 \\
\hline \multicolumn{6}{|c|}{ Number of days spend in the } \\
\hline \multirow[t]{2}{*}{ boat for a trip } & $(n=438)$ & 262 & 59.8 & & \\
\hline & $(\mathrm{n}=27)$ & 18 & 66.6 & 0.49 & 0.48 \\
\hline \multicolumn{6}{|l|}{ Type of boat } \\
\hline Single day motor boat & $(\mathrm{n}=245)$ & 150 & 61.0 & & \\
\hline Other boats & $(n=220)$ & 130 & 59.0 & 0.22 & 0.64 \\
\hline \multicolumn{6}{|l|}{ Service duration } \\
\hline$\leq 10$ years & $(\mathrm{n}=94)$ & 50 & 53.2 & & \\
\hline$>10$ years & $(n=371)$ & 230 & 62.0 & 2.42 & 0.12 \\
\hline \multicolumn{6}{|l|}{ Ethnicity } \\
\hline Sinhalese & $(n=286)$ & 179 & 62.6 & & \\
\hline Non-Sinhalese & $(n=179)$ & 101 & 56.4 & 1.64 & 0.20 \\
\hline \multicolumn{6}{|l|}{ Religion } \\
\hline Catholics & $(n=372)$ & 227 & 22.0 & & \\
\hline Non-Catholics & $(n=93)$ & 53 & 35.6 & 19.8 & $<0.001$ \\
\hline \multicolumn{6}{|l|}{ Education level } \\
\hline Up to grade 5 & $(\mathrm{n}=193)$ & 114 & 59 & & \\
\hline Grade 6 and above & $(n=272)$ & 166 & 61 & .18 & 0.67 \\
\hline
\end{tabular}

\section{Discussion}

\section{Prevalence of accidental injuries}

The present study has revealed that the prevalence of accidental injuries as $19.6 \%$. The most common type of the accident injury was lacerations $(11.4 \%)$. The most common sites of the accident injuries were the arm (11.4\%). A study conducted in North Carolina reported that the prevalence of the injury in previous 12 months was $38.6 \%$ and half of these occurred in arms as in our study (7). The low prevalence in our study may be due to the less recall period (6 months) as well as variation in the fishing mechanism and the type of the fishing.

The work-related injuries and diseases of fishermen are related to the nature of fishing operations and employment arrangements with 
prolong working hours. The risk of accidents to the fishermen working on small fishing vessel is high, due to carrying out many tasks at the same time. Injuries can be related to the vessel itself or to personnel accidents not involving loss or damage to the vessel. Falls and striking on moving objects are very common accidents. Bad weather conditions can increase the risk of accidents or an accident may be due to the human factors like inattention, fatigue, lack of training (2).

\section{Prevalence of hypertension}

Prevalence of hypertension was $24.3 \%$ in the present study. Among the hypertensive fishermen a significant number (24.1\%) was in stage I and only $0.2 \%$ was in stage II hypertension. Kirkutis. et al (9) reported that prevalence of hypertension in Lithuanian seamen was $44.9 \%$, with stage I $30.1 \%$, stage II $10.9 \%$ and stage III was $0.9 \%$. The increase in prevalence of hypertension in later study may be due to differences in risk factors. We found that prevalence of hypertension were significantly higher among those who have $>10$ years' service experience in the fishing sector and history of smoking $>10$ years duration. Consistent to our findings Kirkutis et al reported that statistically significant association of increasing duration of the service and $>15$ years of smoking with hypertension (9). In contrast to our findings increase age of the seamen, current alcohol consumption at least once a week and BMI $>25 \mathrm{~kg} / \mathrm{m} 2$ had statistically significant association with hypertension (9). According to a population based study conducted in 2005 (14), the prevalence of hypertension among the age group 30 to 65 years in four provinces in Sri Lanka was $18.8 \%$, which indicate that prevalence was higher among fishermen

Living and working space on fishing vessels can be quite limited. Further limited crew accommodation can result in fishermen living very close to each other, and this may increase stress.(3) Stress can also increase due to factors like separation from family for a long period, heavy work for a longer duration of time. Stress is a known risk factor for hypertension as well as for other NCDs. One of the limitations of our study was we couldn't assess the level of stress of the fishermen.

\section{Prevalence of overweight and obesity}

Overweight has become a major emerging health problem. It is a known risk factor for many of NCDs. The prevalence of the overweight and obesity was $20.6 \%$ and $2.6 \%$ respectively. Prevalence of obesity was reported as $20.3 \%$ in four provinces in Sri Lanka (14) and this was higher than our study. A study done in Denmark has revealed that the prevalence of the overweight among the fishermen was $73.6 \%$ (10). The high prevalence of the overweight in the Danish study may be due to the different time period of the study and differences of the socio-economic factors of the two countries.

\section{Prevalence of smoking}

In our study the prevalence of ever smoking was $56.8 \%$ and the current smoking was $54.6 \%$. Kalulanda et al (15) revealed the prevalence of overall, urban and rural smoking among general population in Sri Lanka as $18.3 \%, 17.2 \%$ and $18.5 \%$ respectively, which were far lower than the fishermen. Consistent to our findings Kirkutis et al. reported 55.2\% smokers among seamen (9). Lawrie et al reported the prevalence of current smoking in Scotland fishermen as 38.4\%.(11) The low prevalence of current smoking in the later study may be due to the low response rate (57\%) (11). Further Rotti also reported low prevalence of smokers among fishermen $(21.8 \%)$ than non-fishing community $(27.2 \%)(16)$. In contrast a Indian study reported much higher (74.3\%) smokers among fishermen (17).

\section{Prevalence of alcohol consumption}

We found that the prevalence of ever alcoholics 
was $61 \%$ and the prevalence of current alcohol drinkers was $60 \%$. Prevalence of current alcohol consumption in Colombo and Polonnaruwa districts were $32.9 \%$ and $20.8 \%$ respectively (18) which were much lower than the fishing community. Another population based study also revealed that prevalence of current alcohol consumption among Sri Lankans was 30\% (19). Consistent of our findings a study in India reported $63,4 \%$ of fishermen consumed alcohol(17). Rotti (16) and Lawrie et al (11) reported that $61 \%$ and $80.6 \%$ of the fishermen were alcohol consumers respectively. Kirkutis et al reported $80.2 \%$ of seamen were alcohol consumers (9).

As we recruited a representative sample from the population of fishermen, it is possible to generalize the finding to the population. Even though the standard techniques were applied in measuring blood pressure and BMI, risk of information bias was still possible. In conclusion prevalence of accidental injuries, hypertension, overweight, obesity, current smoking and alcohol consumption were higher among fishermen. If proper health promotional and better screening methods have been provided many of the conditions could have been prevented.

\section{Conflicts of interest}

None declared

\section{References}

1. Roberts SE, Rodgers SE, Williams JC. Mortality from disease among fishermen employed in the UK fishing industry from 1948 to 2005. Internat. Marit. Health, $2007,58,1-4$

2. International Labour Organization. Safety and health in the fishing industry. International labour office Geneva.1999
3. Kaerlev, L. et al. Hospital contacts for injuries and musculoskeletal diseases among seamen and fishermen. $B M C$ Musculoskeletal disorders. 2008: 9:8 doi:10.1186/1471-2474-9-8.

4. Roberts SE. Britain's most hazardous occupation: commercial fishing. Accid Anal Prev. 2010 ;42(1):44-9. doi: 10.1016/j.aap.2009.06.031. Epub 2009 Jul 23.

5. Thomas TK, Lincoln JM, Husberg BJ, Conway GA. Is it safe on deck? Fatal and non-fatal workplace injuries among Alaskan commercial fishermen. Am J Ind Med. 2001 Dec;40(6):693-702.

6. Casson FF, et al. Work and chronic health effects among fishermen in Chioggia, Italy. Giornale Italiano di Medicina del Lavoro Ergonomia. 1998; 20(2);68-74.

7. Marshall SW, et al. Work related injuries in small scale fishing. Injury prevention. 2004; 10;217-221. doi: 10.1136/p.2003.005058.

8. European Agency for Safety and Health at Work. Help for Small and Medium Enterprises-Fisheries Sector. (online) Available from http://osha.europa.eu/ en/sub/sme/products/fisheries/index.htm (accessed on 10th September 2011).

9. Kirkutis A, Norkiene S, Griciene P, Gricius J, Yang S, Gintautas J. Prevalence of hypertension in Lithuanian mariners. Proc West Pharmacol Soc. 2004; 47:7175

10. Hansen HL, Hjarnoe L, Jepsen JR. Obesity continues to be a major health risk for Danish seafarers and fishermen. International Maritime Health. 2011; 62(2):98-103. 
11. Lawrie T, et al. The health and life style of Scottish fishermen: a need for health promotion. Health Education Research. 2004;19(4);373-379.

12. Ministry of Fisheries and Aquatic Resources, 2009. Fisheries Statistics Sri Lanka. Statistic unit. Ministry of Fisheries and Aquatic Resources.

13. Harshani SRAP, Abeysena HTCS, Musculoskeletal symptoms, skin disorders and visual impairment among fishermen in the Divisional Secretariat Division of Kalpitiya. Ceylon Medical Journal. 2015; 60(3), 90-94.

14. Wijewardene K, Mohideen MR, Mendis S, Fernando DS, Kulathilaka T, Weerasekara D, Uluwita. Prevalence of hypertension, diabetes, obesity; baseline findings of a population based survey in 4 provinces in Sri Lanka. Ceylon medical journal. 2005; 50(2);62-70.

15. Kalulanda P, Wickramasinghe K, Mahesh JG, Rathnapala A, Constantine GR, Sherrif R, Mathews DR, Fernando SS. Prevalence and correlates of tobacco smoking in Sri Lanka. Asia Pacific Journal of Public Health. 2011; 23(6);861-9.

16. Rotti SB. Jainsankar TJ. Distribution of certain diseases among fishermen in Pondicherry a comparative study. Jawaharlal Institute of Post Graduate Medical Education and Research, Pondicherry, 2002- 2003.

17. Bhondve A, Mahajan H, Sharma B, Kasbe A. Assessment of Addictions among Fishermen in Southern-East Costal Area of Mumbai, India. Journal of Dental and Medical Sciences 2013;6(6); 71-79.

18. de Silva V, Samarasinghe D, Gunawardena N. Alcohol and tobacco use among males in two districts in Sri Lanka. Ceylon Medical Journal. 2009; 54(6);119-124

19. Obot IS, Room R. Alcohol, Gender and Drinking Problems Perspectives from Low and Middle Income Countries. Geneva: World Health Organization. 2005. ISBN 9241563028 . 